\title{
Two novel CMY-2-type $\beta$-lactamases encountered in clinical Escherichia coli isolates
}

\author{
Vera Manageiro ${ }^{1,2}$, Eugénia Ferreira ${ }^{1}$, Margarida Pinto ${ }^{3,6}$, Fernando Fonseca ${ }^{4,7}$, Mónica Ferreira? $^{1}$ \\ Richard Bonnet ${ }^{5}$ and Manuela Caniça ${ }^{1 *}$
}

\begin{abstract}
Background: Chromosomally encoded AmpC $\beta$-lactamases may be acquired by transmissible plasmids which consequently can disseminate into bacteria lacking or poorly expressing a chromosomal bla $a_{\mathrm{Ampc}}$ gene. Nowadays, these plasmid-mediated AmpC $\beta$-lactamases are found in different bacterial species, namely Enterobacteriaceae, which typically do not express these types of $\beta$-lactamase such as Klebsiella spp. or Escherichia coli. This study was performed to characterize two $E$. coli isolates collected in two different Portuguese hospitals, both carrying a novel CMY-2-type $\beta$-lactamase-encoding gene.

Findings: Both isolates, INSRA1169 and INSRA3413, and their respective transformants, were non-susceptible to amoxicillin, amoxicillin plus clavulanic acid, cephalothin, cefoxitin, ceftazidime and cefotaxime, but susceptible to cefepime and imipenem, and presented evidence of synergy between cloxacilin and cefoxitin and/or ceftazidime. The genetic characterization of both isolates revealed the presence of bla $a_{\mathrm{CMY}-46}$ and bla $a_{\mathrm{CMY}-50}$ genes, respectively, and the following three resistance-encoding regions: a Citrobacter freundii chromosome-type structure encompassing a

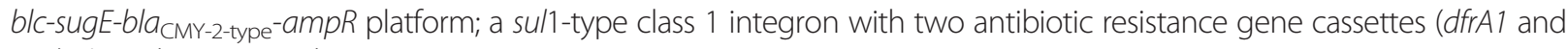
aadA1); and a truncated mercury resistance operon.
\end{abstract}

Conclusions: This study describes two new bla $a_{C M Y-2-t y p e}$ genes in E. coli isolates, located within a C. freundii-derived fragment, which may suggest their mobilization through mobile genetic elements. The presence of the three different resistance regions in these isolates, with diverse genetic determinants of resistance and mobile elements, may further contribute to the emergence and spread of these genes, both at a chromosomal or/and plasmid level.

Keywords: $\beta$-lactamase, Resistance regions, Genetic environment, Escherichia coli

\section{Background}

AmpC $\beta$-lactamases, along with Class A $\beta$-lactamases, are a major group of clinically important enzymes $[1,2]$. They belong to class $\mathrm{C}$ according to the Ambler classification and to group 1 following the functional classification of Bush-Jacoby [3,4], whose prevalence is increasing worldwide [1]; these $\beta$-lactamases are associated with infections caused by pathogenic Gram-negative bacteria, particularly Escherichia coli and Klebsiella pneumoniae. The identification of isolates containing plasmid-mediated AmpC- $\beta$ lactamase (PMA $\beta)$ is epidemiologically and clinically relevant due to the limitations of treatment options [5].

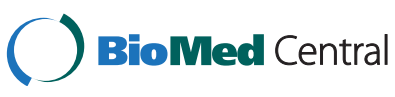

* Correspondence: manuela.canica@insa.min-saude.pt

'Department of Infectious Diseases, National Reference Laboratory of Antibiotic Resistances and Healthcare Associated Infections, National Institute of Health Dr. Ricardo Jorge, Av. Padre Cruz, 1649-016 Lisbon, Portugal Full list of author information is available at the end of the article
AmpC enzymes hydrolyse amino- and ureidopenicillins, and cephamycins (cefoxitin and cefotetan) and, at a low level, oxyiminocephalosporins (ceftazidime, cefotaxime, and ceftriaxone) and aztreonam: they are not inhibited by $\beta$ lactamase inhibitors such as clavulanic acid [1]. AmpCproducing isolates are susceptible to carbapenems and to zwitterionic cephalosporins (cefepime and cefpirome).

In this study, we performed the phenotypic and molecular characterization of two new CMY-2-types (designated CMY-46 and CMY-50), both encoded by probably chromosomal inducible $a m p C$ genes, produced by two clinical $E$. coli isolates. The genetic environment of $b l a_{\mathrm{CMY}-46}$ and bla ${ }_{\mathrm{CMY}-50}$ was also investigated. (c) 2015 Manageiro et al.; licensee BioMed Central. This is an Open Access article distributed under the terms of the Creative Commons Attribution License (http://creativecommons.org/licenses/by/4.0), which permits unrestricted use, distribution, and reproduction in any medium, provided the original work is properly credited. The Creative Commons Public Domain Dedication waiver (http://creativecommons.org/publicdomain/zero/1.0/) applies to the data made available in this article, unless otherwise stated. 


\section{Methods}

\section{Bacterial isolate collection}

Two clinical E. coli strains (INSRA1169 and INSRA3413) were isolated, in 1999, from urine samples of two patients of 77 years and 7 months old, in two different hospitals in Portugal. E. coli DH5 $\alpha$ (pBK-CMY-2) strain was used as control for antimicrobial susceptibility tests.

\section{Antimicrobial susceptibility tests}

Minimal inhibitory concentrations were determined by a microdilution method according to guidelines of the French Society of Microbiology (SFM 2013, http://www. sfm-microbiologie.org/) against seven $\beta$-lactams, alone or in combination with clavulanic acid, and against ciprofloxacin, gentamicin and trimethoprim. Isolates non-susceptible to one third-generation cephalosporin, cefoxitin and/or exhibiting synergy with boronic acid and/or cloxacillin, were considered as presumptive AmpC producers. Imipinem and clavulanic acid were used in order to identify induction effect of AmpC [1,6]. Disks of inducing agents (imipenem $10 \mu \mathrm{g}$ and amoxicillin plus clavulanic acid $25+$ $10 \mu \mathrm{g}$ ) and disks of cephalosporins (cefotaxime $30 \mu \mathrm{g}$ and ceftazidime $30 \mu \mathrm{g}$ ) were placed on Mueller-Hinton agar plates, $20 \mathrm{~mm}$ apart. Positive induction was demonstrated by the antagonism effect surrounding the cephalosporin disks adjacent to the inducers.

\section{Isoelectric point determination}

$\beta$-Lactamases were characterized by isoelectric focusing of ultrasonicated bacterial extracts with the control strains expressing pI 5.2, 5.6, 7.6, 9.0, 9.2, as previously described [7].

\section{Molecular characterization of ampC and ESBL-encoding genes}

The presence of acquired $a m p C\left(b l a_{\mathrm{CMY}}, b l a_{\mathrm{MOX}}, b l a_{\mathrm{FOX}}\right.$, $\left.b l a_{\mathrm{LAT}}, b l a_{\mathrm{ACT}}, b l a_{\mathrm{MIR}}, b l a_{\mathrm{DHA}}, b l a_{\mathrm{MOR}}, b l a_{\mathrm{ACC}}\right)$ and $b l a_{\mathrm{ESBL}}$ genes $\left(b l a_{\mathrm{TEM}}, b l a_{\mathrm{SHV}}, b l a_{\mathrm{OXA}-1 \text {-type }}, b l a_{\mathrm{CTX}-\mathrm{M}}\right)$ was investigated by multiplex PCR assays with primers and conditions as described elsewhere [7-10], and those from Table 1. Controls were included in all assays.

\section{Gene transfer experiments}

Transferability of the $b l a_{\mathrm{CMY}}$ genes was attempted by both broth mating-out assays and electroporation. Conjugation experiments were performed at $37^{\circ} \mathrm{C}$, using recipient strains E. coli $\mathrm{C} 600 \mathrm{Rif}^{\mathrm{R}}, \mathrm{Str}^{\mathrm{R}}$ and E. coli $\mathrm{J} 53 \mathrm{NaN}_{3}{ }^{\mathrm{R}}$, according to the antibiotic susceptibilities of the clinical isolates used as donor. Transconjugants were selected on MacConkey agar plates containing $250 \mu \mathrm{g} / \mathrm{ml}$ of rifampicin, $160 \mu \mathrm{g} / \mathrm{ml}$ of streptomycin or $160 \mu \mathrm{g} / \mathrm{ml}$ of sodium azide plus $10 \mu \mathrm{g} / \mathrm{ml}$ of cefoxitin. Plasmid DNA was extracted from clinical strains, using the Wizard Plus Midipreps DNA Purification kit (Promega), and used to transform electrocompetent $E$. coli $\mathrm{DH} 5 \alpha \Delta a m p C$ by electroporation, as previously described [7]. Transformants were selected on Luria broth medium containing $10 \mu \mathrm{g} /$ $\mathrm{ml}$ of cefoxitin.

\section{Cloning experiments}

The $b l a_{\mathrm{CMY}-2}, b l a_{\mathrm{CMY}-46}$ and $b l a_{\mathrm{CMY}-50}$ genes were amplified with iProof $^{\text {TM }}$ High-Fidelity DNA Polymerase (Bio-Rad, Hercules, CA), using primers from Table 1. Amplicons (1169 bp) were ligated in the SmaI site of the phagemid pBK-CMV (Stratagene) downstream of its inducible lacZ promoter and transformed into electrocompetent E. coli DH5 $\alpha \Delta a m p C$ cells. A gene Pulser II apparatus (Bio-Rad, Hercules, CA) was used for standard electroporation techniques, as previously described [7]. Recombinant bacteria were selected on LB agar plates containing $10 \mu \mathrm{g} / \mathrm{ml}$ of cefoxitin.

\section{Genetic background characterization}

The presence of class 1 integrons was determined in both isolates through PCR amplification of the integrase-specific intI1 gene with the same specific primers and conditions as reported previously [11] (Table 1). PCR-mapping and sequencing of the genetic environment of bla $a_{\mathrm{CMY}-46}$ and $b l a_{\mathrm{CMY}-50}$ was performed using primers targeting genes known for promoting antibiotic resistance and integrons (Table 1). Sequence alignments and generation of resistance cassette contigs were performed using Bionumerics (Applied Maths). Gene identity was confirmed at the NCBI website (http://www.ncbi.nlm.nih.gov/).

\section{Findings}

The two clinical E. coli isolates INSRA1169 and INSRA3413 were resistant to amoxicillin, amoxicillin plus clavulanic acid, cephalothin, cefoxitin, ceftazidime, cefotaxime, gentamicin and trimethoprim, but susceptible to cefepime and imipenem (Table 2). INSRA1169 was also nonsusceptible to ciprofloxacin. Synergy between cloxacillin and cefoxitin plus cefotaxime and boronic acid, along with the absence of synergy between extended-spectrum cephalosporins and clavulanic acid, suggest that the resistance to extended-spectrum cephalosporins was mediated by the overproduction of AmpC $\beta$-lactamases. The resistance phenotype was not transferable, neither in conjugation assays with $E$. coli $\mathrm{C} 600$ as a recipient, or in transformation assays by electroporation of plasmid-DNA preparations into $E$. coli $\mathrm{DH} 5 \alpha$. This might suggest a chromosomal location of AmpC-encoding genes.

Transformants, obtained after cloning of DNA amplicons of INSRA1169 and INSRA3413 in pBK-CMV plasmid vector (Figure 1a), showed a resistance phenotype similar to that of clinical isolates. However, they were susceptible to ciprofloxacin, gentamicin and trimethoprim, like the control strain E. coli DH5 $\alpha$ (pBK-CMY-2) 
Table 1 Primers, drawn in this study, used for PCR amplification and sequencing of PMA $\beta$ genes and for PCR mapping of bla ${ }_{\mathrm{CMY}-46}$ and bla $\mathrm{CMY-50}$

\begin{tabular}{|c|c|c|c|}
\hline \multirow[t]{2}{*}{ Gene (s) } & \multicolumn{2}{|l|}{ Primer Sequence $\left(5^{\prime} \rightarrow 3^{\prime}\right)$} & \multirow{2}{*}{$\begin{array}{l}\text { PCR product } \\
\text { (bp) / Method }\end{array}$} \\
\hline & Forward & Reverse & \\
\hline bla & TTACGGAACTGATTTCATG & TCGTCAGTTATTGCAGC & 1169 / PCR + Seq. \\
\hline orf513 & GCCAGGTCTTGAGTATCGTC & CATGTAATTGAGTCAGCGTATC & $363 / P C R+$ Seq. \\
\hline$f d r B-f d r D$ & CTCAGTTGACCACCACGAAC & GAATGCCAATAGCCGTTACGAC & $920 /$ PCR + Seq. \\
\hline$f d r B-a m p R$ & CTCAGTTGACCACCACGAAC & CACCAGTCAGAATGTTCACGCA & 1140 / PCR + Seq. \\
\hline$a m p R-b l a_{C M Y-G 2}$ & TGCGTGAACATTCTGACTGGTG & TTCTCCTGAACGTGGCTGGC & 1660 / PCR + Seq. \\
\hline bla $a_{C M Y-G 2}-s u g E$ & TGGCCAGAACTGACAGGCAAA & ATGTCCTGGATCGTTITATTA & $1751 /$ PCR + Seq. \\
\hline merA- urf2 & TTCCCCTACCTGACGATGG & TGTTGCAGGCAGGAATAGC & 1214/ PCR + Seq. \\
\hline merR - merA & TCTTTCTCCCCTTGCAGCG & CACCTTGTCGAACAGCCCA & Variable / PCR + Seq. \\
\hline merA & CGTCCAATCTGCCATAGTG & GTAGGGGAACAACTGGTCG & Seq. \\
\hline merD & CCTTCGAGGCGGGTATC & CCGATACCCGCCTCGAAG & Seq. \\
\hline
\end{tabular}

${ }^{a}$ Method used for screening and/or identification of genes: M-PCR, Multiplex-PCR; Seq, sequencing; PCR + Seq, PCR and sequencing.

(Table 2). Both the clinical strains and the transformants produced $\beta$-lactamases exhibiting an alkaline isoelectric point (pI 9.2) compatible with AmpC-type $\beta$-lactamases. Indeed, PCR revealed the absence of $b l a_{\mathrm{ESBL}}$ genes plus the presence of chromosomal $E$. coli ampC-type gene; the sequence of cloned DNA fragments identified two new CMY-2-like genes, which were not related to chromosome-mediated E. coli AmpC gene. The chromosomal location of such genes has only been observed in Salmonella spp. and Proteus mirabilis isolates [12-14].

The deduced amino acid sequences confirmed that the new genes encoding the $\beta$-lactamases CMY-46 (in INSRA1169) and CMY-50 (in INSRA3413), which were new variants of CMY-2, differed by 9 and 13 amino acid substitutions, respectively (Table 3). Two of these mutations (Q193K plus P208A for CMY-46 and N194S plus D198N for CMY-50) are in the $\Omega$ loop (between amino acids 178 and 226), which interacts by hydrogen bonding with helix $\mathrm{H}-2$ close to the active Ser64. Substitutions in this region have been linked to the extension of the hydrolysis spectrum [15]. However, CMY-46 and
CMY-50 $\beta$-lactamases did not confer resistance to cefepime and conferred low level of resistance to ceftazidime and cefotaxime, which suggests that, in contrast to extended-spectrum AmpCs, they have moderate or no extended-spectrum activity (Table 2) [15-18].

The study of sequences surrounding $b l a_{\mathrm{CMY}-46}$ and $b l a_{\mathrm{CMY}-50}$ revealed the presence of the $b l c$ gene (encoding an outer membrane lipoprotein) and the $s u g E$ gene (encoding a small MDR protein responsible for resistance to quaternary ammonium compounds) downstream of their open reading frames (Figure 1a). Upstream, an $a m p R$ gene encoding the usual transcriptional regulator of $a m p C$ genes was observed in an opposite direction of transcription (Figure 1a). The presence of an intact $a m p C$ - $a m p R$ segment in both new $b l a_{\mathrm{CMY}}$ genetic regions implied that the production of CMY-46 and CMY-50 is inducible, which was corroborated by the used phenotypic induction method. This ampC$a m p R$ region was identical to the sequence flanking the $b l a_{\mathrm{AmpC}}$ gene in the $C$. freundii chromosome [6], except for $\mathrm{AmpR}_{\mathrm{CMY}-46}$ (that had 4 amino acid substitutions), but none were located in the helix-turn-helix region or in other

Table 2 MICs of antibiotics for CMY-46- and CMY-50-producing E. coli isolates and E. coli transformants and recipients ${ }^{a}$

\begin{tabular}{|c|c|c|c|c|c|c|c|c|c|c|c|c|}
\hline \multirow[t]{2}{*}{ E. coli strain } & \multicolumn{12}{|c|}{ MIC $(\mu \mathrm{g} / \mathrm{ml})^{\mathrm{b}}$} \\
\hline & AMX & AMC $^{\mathrm{C}}$ & $\mathrm{CF}$ & CAZ & $\mathrm{CCAZ}^{\mathrm{C}}$ & CTX & FEP & FOX & IMP & CIP & GEN & TMP \\
\hline $\mathrm{DH} 5 \mathrm{a} \Delta a m p C$ & 8 & 8 & 8 & 0.25 & 0.125 & 0.06 & 0.03 & 4 & 0.25 & $\leq 0.125$ & $\leq 0.125$ & $\leq 0.25$ \\
\hline DH5a (pBK-CMY-2) & $>2048$ & $>2048$ & 1024 & 32 & 16 & 8 & 0.25 & 64 & 0.5 & $\leq 0.125$ & 1 & $\leq 0.25$ \\
\hline INSRA1169 (CMY-46 + TEM-1) & $>2048$ & $>2048$ & 1024 & 16 & 4 & 4 & 0.032 & 64 & 2 & 4 & $>128$ & $>128$ \\
\hline DH5a (pBK-CMY-46) & $>2048$ & $>2048$ & 1024 & 32 & 4 & 8 & 0.25 & 64 & 0.5 & $\leq 0.125$ & 2 & $\leq 0.25$ \\
\hline INSRA3413 (CMY-50) & $>2048$ & $>2048$ & 1024 & 16 & 8 & 4 & 0.25 & 64 & 2 & $\leq 0.125$ & 64 & 64 \\
\hline DH5a (pBK-CMY-50) & $>2048$ & $>2048$ & 1024 & 16 & 8 & 4 & 0.25 & 64 & 0.5 & $\leq 0.125$ & 0.5 & $\leq 0.25$ \\
\hline
\end{tabular}

${ }^{\mathrm{a}} E$. coli EcDH5a (pBK-CMY-2) was control strain; E. coli DH5a (pBK-CMY-46) and E. coli DH5a (pBK-CMY-50) were transformants of E. coli INSRA1169 (harboring CMY-46 and TEM-1 enzymes) and E. coli INSRA3413 (harboring CMY-50 enzyme), respectively; E. coli EcDH5a was the recipient strain.

${ }^{\mathrm{b}} \mathrm{AMX}$, amoxicillin; AMC, amoxicillin-clavulanic acid; CF, cephalothin; CAZ, ceftazidime; CCAZ, ceftazidime-clavulanic acid; CTX, cefotaxime; FEP, cefepime; FOX, cefoxitin; IMP, imipenem; CIP, ciprofloxacin; GEN, gentamicin and TMP, trimethoprim.

${ }^{c}$ Clavulanic acid, at fixed concentration of $2 \mu \mathrm{g} / \mathrm{ml}$. 


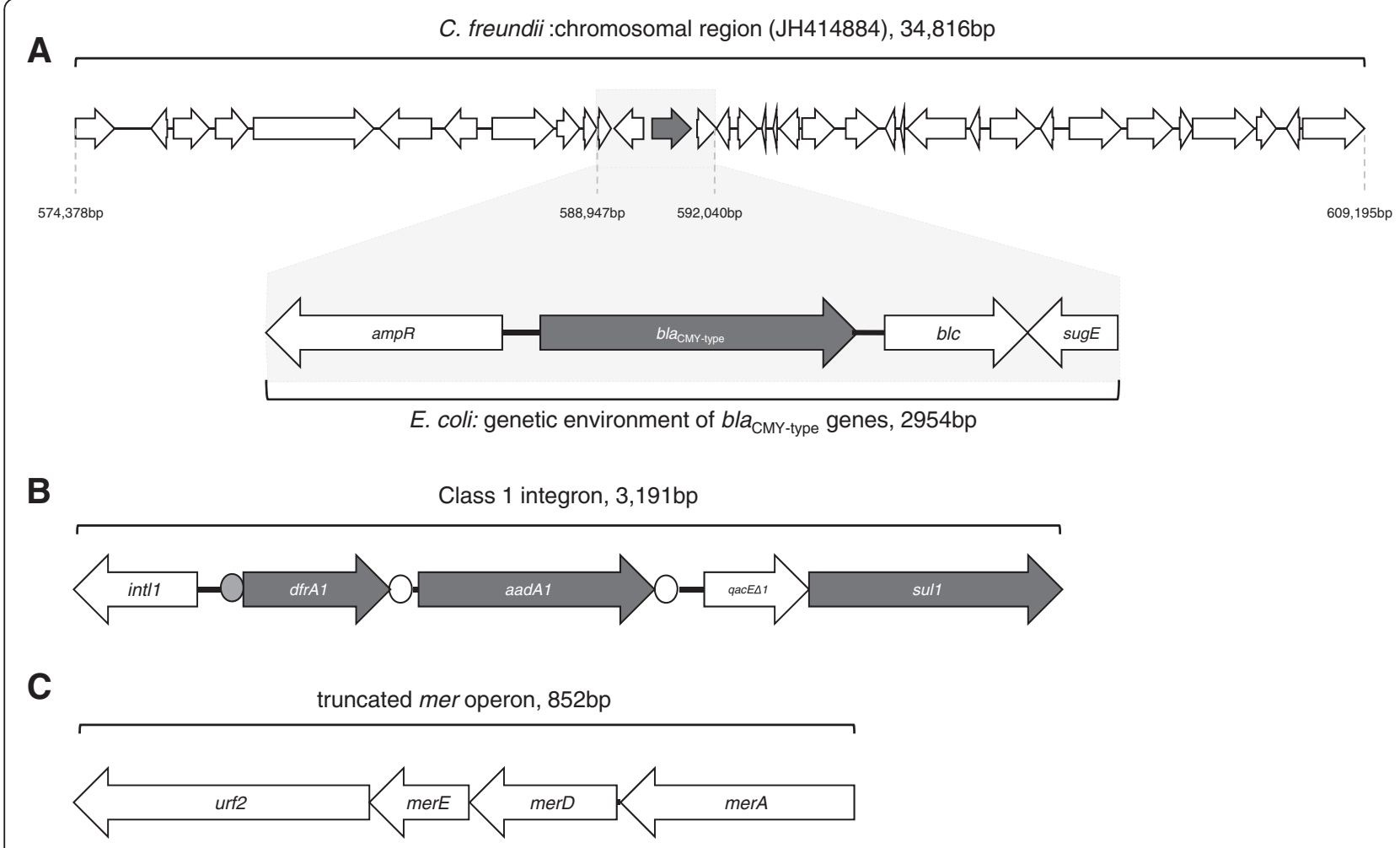

Figure 1 Schematic representation of the same three structures found within clinical isolates expressing $b / a_{\mathrm{CMY}-46}$ and $b / a_{\mathrm{CMY}-50}$. The directions of transcription of the corresponding genes are depicted by arrows. A: sequence, including the genetic environment of bla $a_{\mathrm{CMY}-\mathrm{type}}$ genes, compared with C. freundii chromosomal region (GenBank JH414884); B: class 1 integron, with att/1 site (grey circle) and the two attc regions (open circles); C: truncated mercury resistance operon.

positions related to AmpR function [20,21]. The promoter regions of our $b l a_{\mathrm{CMY}-2 \text {-type }}$ and $a m p R$ genes harbored no sequence element associated with increased strength of the promoter [20,21]. In addition, the $f r d D$, frd $C$, and $\operatorname{fr} d B$ genes that are usually adjacent to $a m p C-a m p R$ in the $C$. freundii chromosome were not identified in the sequences flanking bla $a_{\mathrm{CMY}-46}$ or bla $a_{\mathrm{CMY}-50}$.

Class 1 integrons, also detected in INSRA1169 and INSRA3413 (Figure 1b), comprised the integrase-encoding gene intI1, two gene cassettes, aacA1 and $d$ frA1, and qacE $\Delta 1$ plus sul1, which were probably responsible for the observed resistances to trimethoprim and aminoglycosides.
We also found a truncated mercury resistance operon (Figure 1c), which was previously reported as belonging to a "kan region" that included a kanamycin resistance gene [22]. This finding is of concern since mercury resistance may help to promote antibiotic resistance through indirect selection [23].

In summary, this study describes two new bla $a_{\mathrm{CMY}-2 \text {-type }}$ genes located within a $C$. freundii-derived fragment. Considering that CMY-type $\beta$-lactamases, detected in $E$. coli, are derived from the $C$. freundii chromosomal AmpC [1] and that chromosome-derived genes are usually mobilized by MGE [24,25], the presence of three

Table 3 Comparison of amino acid substitutions of two new CMY-type $\beta$-lactamases

\begin{tabular}{|c|c|c|c|c|c|c|c|c|c|c|c|c|c|c|c|c|c|c|c|c|c|c|}
\hline \multirow[t]{4}{*}{ РMA $\beta$} & \multicolumn{20}{|c|}{ Amino acid at position no. ${ }^{a}$} & \multirow[t]{4}{*}{ pl } & \multirow{4}{*}{$\begin{array}{l}\text { Accession } \\
\text { Number }\end{array}$} \\
\hline & 3 & 3 & 4 & 1 & 1 & 1 & 1 & 1 & 1 & 1 & 1 & 1 & 1 & 1 & 2 & 2 & 2 & 2 & 2 & 3 & & \\
\hline & \multirow[t]{2}{*}{2} & \multirow[t]{2}{*}{5} & \multirow[t]{2}{*}{9} & 0 & 0 & 2 & 2 & 3 & 4 & 6 & 9 & 9 & 9 & 9 & 0 & 3 & 4 & 5 & 6 & 4 & & \\
\hline & & & & 2 & 5 & 4 & 6 & 3 & 3 & 4 & 0 & 3 & 4 & 8 & 8 & 6 & 2 & 3 & 1 & 8 & & \\
\hline CMY-2 & V & Q & A & Q & $R$ & D & $R$ & $\mathrm{H}$ & $\mathrm{T}$ & K & $T$ & Q & $\mathrm{N}$ & $\mathrm{D}$ & $P$ & A & $\mathrm{H}$ & A & $\mathrm{R}$ & V & 9.0 & X91840 \\
\hline CMY-46 & & & $T$ & & $S$ & & $\mathrm{~T}$ & R & A & & & K & & & A & V & $\mathrm{R}$ & & & & 9.2 & FN556186 \\
\hline CMY-50 & I & $E$ & & $\mathrm{R}$ & $S$ & $E$ & $\mathrm{~T}$ & $R$ & & Q & & & $\mathrm{S}$ & $\mathrm{N}$ & & & & $E$ & C & $A$ & 9.2 & FN645444 \\
\hline
\end{tabular}

${ }^{a}$ Numbering according to Bauernfeind et al., 1996 [19]. 
resistance regions with diverse resistance determinants and MGE in this study, suggests the dynamics of bacteria in the transference of antibiotic resistance. In addition, they might also trigger the future emergence and spread of these resistant determinants both at a chromosomal or/and plasmid level.

\section{Availability of supporting data}

The data set supporting the results of this article is included within the article.

\author{
Abbreviations \\ PMAß: Plasmid-mediated AmpC- $\beta$-lactamase; SFM: French Society of \\ Microbiology; MDR: Multidrug-resistance; MGE: Mobile genetic elements; \\ ESAC: Extended-spectrum AmpC cephalosporinases; ESBL: Extended-spectrum \\ B-lactamase.
}

\section{Competing interests}

The authors declare that they have no competing interests.

\section{Authors' contributions}

VM performed the experiments, data interpretation and drafted the manuscript; EF and MF took part in the experiments; MP and FF worked on microbiology and clinical data; RB participated in data interpretation and reviewing of the manuscript; and MC conceived the study, and contributed to data interpretation and reviewing of the manuscript. All authors read and approved the final manuscript.

\section{Acknowledgements}

This study was supported by a grant from the Department of Infectious Diseases, National Institute of Health Dr. Ricardo Jorge (in 2012). V. Manageiro was supported by grant SFRH/BPD/77486/2011 from the Fundação para a Ciência e a Tecnologia, Lisbon, Portugal. This work was funded by "Strategic Plan for Environmental and Natural Sciences, Project UI/ 211-2011-2012" referenced as "Pest-OE/AGR/UI0211/2011" from CECA-ICETA. The GenBank accession numbers for the new AmpC-encoding genes are FN556186 for bla $a_{\mathrm{CMY}-46}$ and FN645444 for bla ${ }_{\mathrm{CMY}-50}$

\section{Author details}

1Department of Infectious Diseases, National Reference Laboratory of Antibiotic Resistances and Healthcare Associated Infections, National Institute of Health Dr. Ricardo Jorge, Av. Padre Cruz, 1649-016 Lisbon, Portugal. ${ }^{2}$ Centre for the Study of Animal Sciences (ICETA), University of Oporto, Oporto, Portugal. 'Laboratory of Microbiology, Hospital Garcia de Orta, EPE, Almada, Portugal. ${ }^{4}$ Laboratory of Clinical Pathology, Hospital de Santa Luzia, Viana do Castelo, Portugal. ${ }^{5} \mathrm{CHU}$ Clermont-Ferrand, Laboratoire de Bactériologie, Clermont-Ferrand, France. ${ }^{6}$ Present address: Laboratory of Microbiology, Centro Hospitalar de Lisboa Central, EPE, Lisbon, Portugal. 'PPresent address: Laboratory of Clinical Pathology, Centro Hospitalar de Póvoa de Varzim-Vila do Conde, EPE, Póvoa de Varzim, Portugal.

Received: 1 October 2014 Accepted: 24 February 2015

Published online: 18 March 2015

\section{References}

1. Jacoby GA. AmpC $\beta$-lactamases. Clin Microbiol Rev. 2009;22:161-82.

2. Rice LB, Bonomo RA. $\beta$-Lactamases: which ones are clinically important? Drug Resist Updat. 2000;3:178-89.

3. Ambler RP, Coulson AF, Frere JM, Ghuysen JM, Joris B, Forsman M, et al. A standard numbering scheme for the class A $\beta$-lactamases. Biochem J. 1991:276:269-70.

4. Bush K, Jacoby GA. Updated functional classification of $\beta$-lactamases. Antimicrob Agents Chemother. 2010;54:969-76.

5. Pai H, Kang Cl, Byeon JH, Lee KD, Park WB, Kim HB, et al. Epidemiology and clinical features of bloodstream infections caused by AmpC-type- $\beta$-lactamaseproducing Klebsiella pneumoniae. Antimicrob Agents Chemother. 2004;48:3720-8.
6. Lindquist S, Lindberg F, Normark S. Binding of the Citrobacter freundii AmpR regulator to a single DNA site provides both autoregulation and activation of the inducible ampC ß-lactamase gene. J Bacteriol. 1989;171:3746-53.

7. Mendonça N, Leitão J, Manageiro V, Ferreira E, Antimicrobial Resistance Surveillance Program in Portugal (ARSIP), Caniça M. Spread of extended-spectrum B-lactamase CTX-M-producing Escherichia coli clinical isolates in community and nosocomial environments in Portugal. Antimicrob Agents Chemother. 2007:54:1946-55

8. Pérez-Pérez FJ, Hanson ND. Detection of plasmid-mediated AmpC $\beta$-lactamase genes in clinical isolates by using multiplex PCR. J Clin Microbiol. 2002:40:2153-62.

9. Jones-Dias D, Manageiro V, Francisco AP, Martins AP, Domingues G, Louro $D$, et al. Assessing the molecular basis of transferable quinolone resistance in Escherichia coli and Salmonella spp. from food-producing animals and food products. Vet Microbiol. 2013;167:523-31.

10. Manageiro V, Ferreira E, Caniça M, Manaia CM. GES-5 among the $\beta$-lactamases detected in ubiquitous bacteria isolated from aquatic environment samples. FEMS Microbiol Lett. 2014;351:64-9.

11. Leverstein-Van Hall MA, Paauw A, Box AT, Blok HE, Verhoef J, Fluit AC. Presence of integron-associated resistance in the community is widespread and contributes to multidrug resistance in the hospital. J Clin Microbiol. 2002:40:3038-40.

12. Shahada F, Sekizuka T, Kuroda M, Kusumoto M, Ohishi D, Matsumoto A, et al. Characterization of Salmonella enterica serovar Typhimurium isolates harboring a chromosomally encoded CMY-2 $\beta$-lactamase gene located on a multidrug resistance genomic island. Antimicrob Agents Chemother. 2011;55:4114-21.

13. Zioga A, Whichard JM, Joyce KJ, Tzelepi E, Tzouvelekis LS, Miriagou V. Evidence for chromosomal and plasmid location of CMY-2 cephalosporinase gene in Salmonella serotype Typhimurium. J Antimicrob Chemother. 2008:61:1389-90.

14. D'Andrea MM, Literacka E, Zioga A, Giani T, Baraniak A, Fiett J, et al. Evolution and spread of a multidrug-resistant Proteus mirabilis clone with chromosomal AmpC-type cephalosporinases in Europe. Antimicrob Agents Chemother. 2011;55:2735-42.

15. Nordmann P, Mammeri H. Extended-spectrum cephalosporinases: structure, detection and epidemiology. Future Microbiol. 2007;2:297-307.

16. Rodríguez-Martínez JM, Poirel L, Nordmann P. Extended-spectrum cephalosporinases in Pseudomonas aeruginosa. Antimicrob Agents Chemother. 2009;53:1766-71.

17. Rodríguez-Martínez JM, Nordmann P, Ronco E, Poirel L. Extended-spectrum cephalosporinase in Acinetobacter baumannii. Antimicrob Agents Chemother 2010;54:3484-8.

18. Rodríguez-Martínez JM, Fernández-Echauri P, Fernández-Cuenca F, Diaz-de-Alba P, Briales A, Pascual A. Genetic characterization of an extended-spectrum AmpC cephalosporinase with hydrolysing activity against fourth-generation cephalosporins in a clinical isolate of Enterobacter aerogenes selected in vivo. J Antimicrob Chemother. 2012;67:64-8.

19. Bauernfeind A, Stemplinger I, Jungwirth $R$, Giamarellou $H$. Characterization of the plasmidic $\beta$-lactamase CMY-2, which is responsible for cephamycin resistance. Antimicrob Agents Chemother. 1996;40:221-4.

20. Bartowsky E, Normark S. Interactions of wild-type and mutant AmpR of Citrobacter freundii with target DNA. Mol Microbiol. 1993;10:555-65.

21. Hanson ND, Sanders CC. Regulation of inducible AmpC $\beta$-lactamase expression among Enterobacteriaceae. Curr Pharm Des. 1999:5:881-94.

22. Call DR, Singer RS, Meng D, Broschat SL, Orfe LH, Anderson JM, et al. bla $a_{\mathrm{CMY}-}$ 2-positive IncA/C plasmids from Escherichia coli and Salmonella enterica are a distinct component of a larger lineage of plasmids. Antimicrob Agents Chemother. 2010;54:590-6.

23. Baker-Austin C, Wright MS, Stepanauskas R, McArthur JV. Co-selection of antibiotic and metal resistance. Trends Microbiol. 2006;14:176-82.

24. Frost LS, Leplae R, Summers AO, Toussaint A. Mobile genetic elements: the agents of open source evolution. Nat Rev Microbiol. 2005;3:722-32.

25. Norman A, Hansen LH, Sørensen SJ. Conjugative plasmids: vessels of the communal gene pool. Phil Trans R Soc B. 2009;364:2275-89. 